Яловенко Е. В., Журавлев В. Н.

Государственное предприятие «Запорожское машиностроительное конструкторское бюро «Прогресс» имени академика А. Г. Ивченко. Украина, г. Запорожье

\title{
ЗВУКОПОГЛОЩАЮЩАЯ ПАНЕЛЬ ГАЗОТУРБИННОГО ДВИГАТЕЛЯ НА БАЗЕ ИРРАЦИОНАЛЬНОГО ЧИСЛА ФИБОНАЧЧИ
}

\begin{abstract}
Предложено решение задачи поглощения шумов, в том числе, для газотурбинных двигателей, методом выделения частотных составляющих иума двигателя, находящихся в иррациональном соотношении, с последующей диссипацией их энергии в элементах конструкции, выполненной из композитных материалов. Экспериментальные исследования показали, ито разработанная звукоизоляционная панель, как минимум, на один децибел мощңости эффективнее традиционных панелей в эффективном звуковом диапазоне частот. Конструкция панели и примененные композитные материалы, в частности углепластик, обеспечивают максимальное поглощение энергии частотных составляющих . [dx.doi.org/10.29010/085.11]
\end{abstract}

Ключевые слова: газотурбинные двигатели; звукопоглощающая панель; углепластик; число Фибоначчи.

\section{1. Введение. Постановка задачи}

Шум самолетов влияет на проживающее вблизи аэропортов население, пассажиров и обслуживающий персонал, создает помехи при приеме и передаче акустической информации, вызывает аномалии в работе приборов и электронной аппаратуры. В связи с этим шумы пассажирских самолетов и вертолетов нормированы стандартами Международной организации гражданской авиации IКАО, а шумы в салоне - национальными стандартами. Эти требования связанны с актуальностью решения задачи уменьшения авиационного шума и негативного влияния его энергии на окружающую среду, которая связана с деятельностью авиации. Международная ассоциация воздушного транспорта одобрила решение Международной организации гражданской авиации о принятии нового стандарта авиационного шума. В соответствии с этим стандартом, допустимый эффективный уровень шума, излучаемого самолетами новых типов, будет снижен на 7 дБ в сравнении с действующим стандартом. Новый стандарт внедрен с 31 декабря 2017 г. и распространяется на самолеты, которые получили сертификат после этой даты.

Традиционно используют два направления борьбы с шумом газотурбинных двигателей (ГТД):

1. Уменьшение шума в источнике, т.е. в элементах конструкции и узлах ГТД, что, как правило, связано со снижением эксплуатационных характеристик ГТД

2. Снижение шума в акустическом канале его распространения от источника к приемнику, с использованием звукопоглощающих конструкций как в проточной части ГТД, так и в ограждающих конструкциях.

Применяемые в настоящее время, звукопоглощающие конструкции представляют собой конструкцию, состоящую из набора резонаторов Гельмгольца (рис. 1). Они имеют небольшую массу, изолируют источник звуковых колебаний от приемника и приемлемые звукопоглощающие характеристики. Недостатком данных панелей является их настройка на узкий диапазон звуковых колебаний и соответственно недостаточная эффективность в других диапазонах частот звуковых волн.

В связи с экологической важностью требований к шумам самолетов гражданской авиации, задача создания звукоизоляционных панелей для газотурбинных двигателей и получение с их помощью технического результата, а именно - повышения эффективности звукопоглощения при соответствии их характеристик действующим международным стандартам диапазона звуковых частот, является актуальной [1].

\section{2. Анализ технико-технологических решений} традиционных звукопоглощающих панелей

Одно и многослойные конструкции звукопоглощающих панелей с сотовым заполнителем, соты которого представляют собой резонаторы Гельмгольца (рис. 1), настроенные на выбранную частоту излучения элементов конструкции, широко применяются при создании ГТД и самолетов всех классов [2].

На основе конструкций с сотовым заполнителем представляется возможным реализовать их пре- 


\section{техниоогические TC 4/2018}

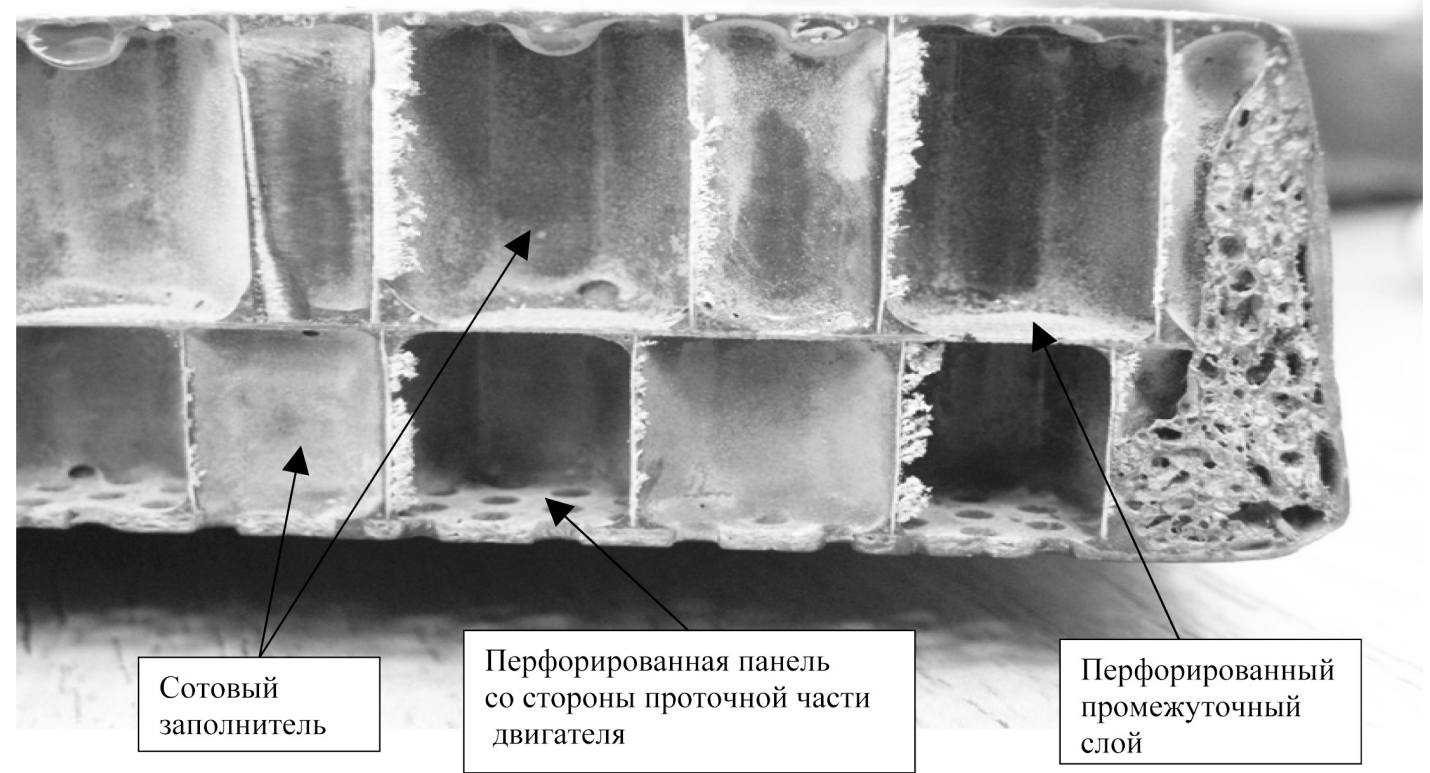

Рис. 1. Конструкция двухслойной панели шумопоглощения ГТД

имущества, такие, как уменьшение массы, увеличение жесткости замкнутых контуров, получить достаточно гладкую поверхность проточной части двигателя. С помощью таких конструкций удается снизить уровень шума в пассажирском салоне и в кабине пилота, а также в отдельных специфических отсеках летательных аппаратов [3].

Большое количество экспериментальных исследований и публикаций, посвященных поиску оптимального эффективного решения задачи снижения уровня шумов на промышленных объектах, в частности авиационных газотурбинных двигателях, свидетельствует об отсутствии системного аналитического подхода, позволяющего провести анализ физического процесса диссипации энергии шума технических объектов и машин в элементах конструкции звукопоглощающих панелей.
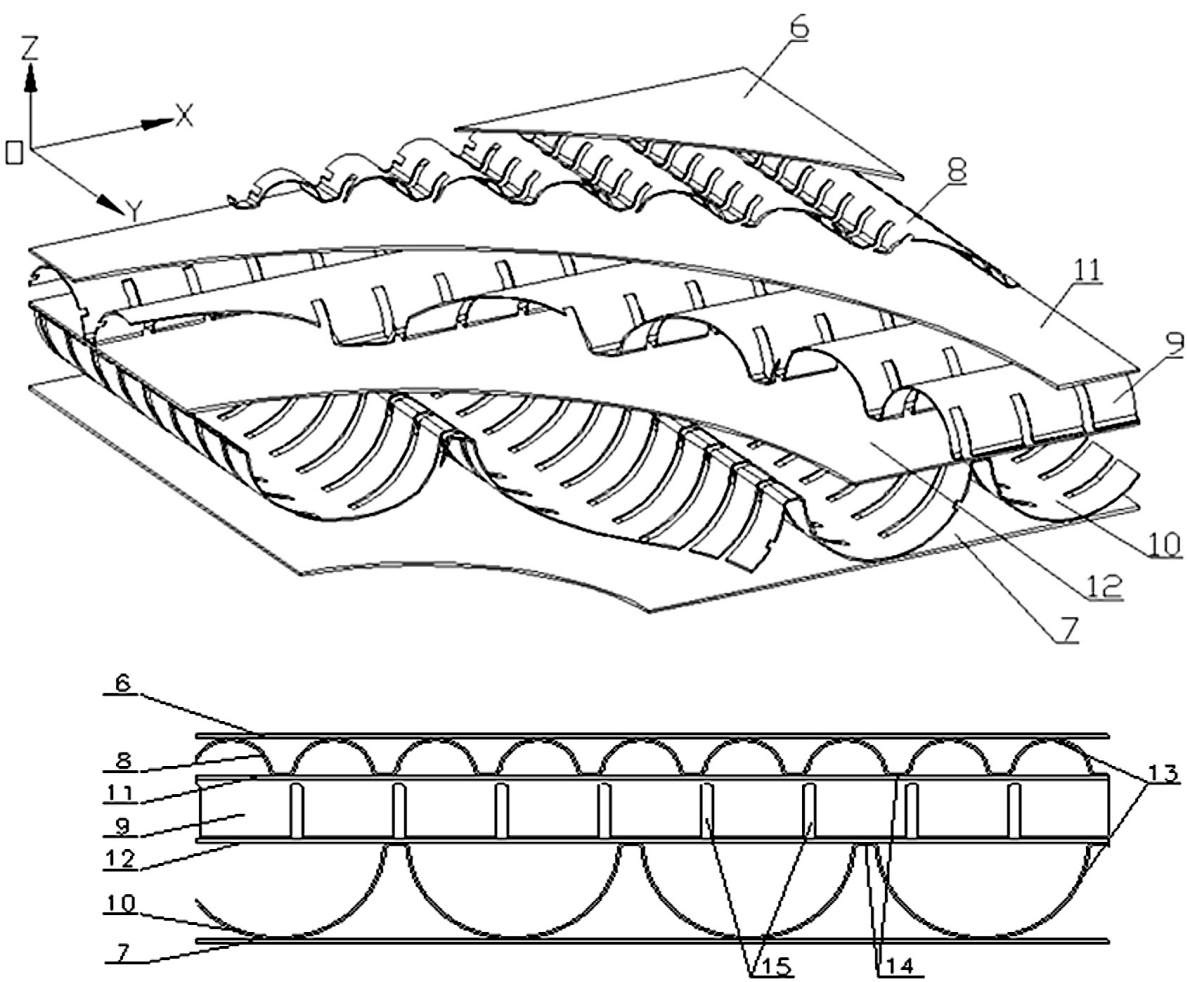

Рис. 2. Конструкция звукопоглощающей панели разработанной ГП «Ивченко-Прогресс»

\section{3. Описание} разработанного конструктивнотехнологического решения

Звукоизоляционная панель ГТД, разработанная в ГП «Ивченко-Прогресс» [6], представляет собой конструкцию (рис. 2), содержащую внутреннюю обшивку 6 , внешнюю обшивку 7 и размещенный между ними многослойный композитный заполнитель, который представляет собой совокупность чередующихся гофрированных слоев (позиции $8,9,10$ ), и разделяющих их промежуточных слоев - позиции 11 и $12 . \mathrm{Ha}$ внутренней обшивке 6 звукоизоляционной панели выполненной из композитного материала, в частности 
из стекло-углепластика, перфорация обшивки отсутствует. Внешняя обшивка 7 изготовлена из материала, который обеспечивает необходимую механическую и термическую прочность всей конструкции панели.

Промежуточные слои 11 и 12 звукоизоляционные, выполняются из композитного звукопоглощающего материала (в частности из углепластика). Каждый из гофрированных слоев 8, 9, 10 представляет собой набор дискретных элементов (размером примерно $(110 \times 110))$ мм, изготовленных из

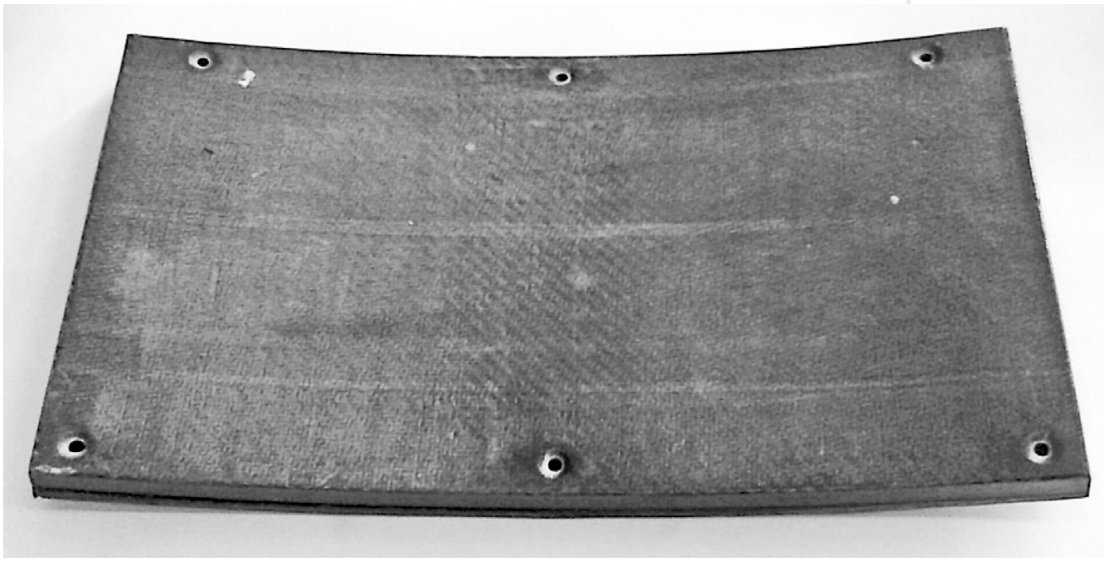

Рис. 3. Экспериментальная панель однослойного КМ на основе углеродной ткани.

Каждый дискретный элемент гофрированного слоя спрофилирован в виде рядов звукоотражающих рефлекторов. Элементы соединяются между собой в шахматном порядке соединением типа «паз-выступ» на клее, и образуют слои звукоотражающих и звукопоглощающих элементов конструкции.

Таким образом, каждый гофрированный слой 8, 9 и 10 представляет собой совокупность параллельных рядов звукоотражающих элементов 13 и соединяющих их поверхностей 14, которые образуют циклические ряды.

В рядах звукоотражающих элементов 13 со стороны соединительных криволинейных поверхностей 14 и перпендикулярно им выполнены пазы 15, которые позволяют изготавливать слои 8, 9 и 10 звукоизоляционной панели двойной переменной кривизны. При этом геометрические параметры (длина, ширина и шаг) описываемых пазов 15 определяются конструктивными и технологическими параметрами, которые обусловлены радиусом кривизны, необходимой прочностью и жесткостью всей звукоизоляционной панели.

Пятислойный композитный заполнитель звукоизоляционной панели, а именно слой 6 , гофрированные слои 8, 9 и 10 и разделяющие их промежуточные слои 11 и 12, выполнены из материала с высоким коэффициентом поглощения акустической энергии, в частности, из углепластика. Использование в составе звукоизоляционной панели функциональных композиционных материалов, которые имеют меньшую плотность в сравнении с традиционными материалами, позволяет снизить массу конструкции панели при сохранении ее прочности и эксплуатационной надежности с одновременным повышением звукопоглощающих параметров.

Благодаря использованию композитных материалов конструкция панели достаточно технологична. При изготовлении деталей поз. 6, 7, 11 и 12 может быть использована одна композитная пресс-форма.

Для деталей поз. 8, 9 и поз. 10 применяются малогабаритные металлические пресс-формы. Окончательная сборка панели выполняется в композитной пресс-форме аналогичной пресс-форме для изготовления поз. 6, 7, 11 и 12 (см. рис. 3). Удельный объемный вес разработанной панели соответствует показателям панелей серийных двигателей.

\section{3. Принцип работы звукоизоляционной панели}

Принцип работы звукоизоляционной панели газотурбинного двигателя заключается в следующем. Энергия, создаваемая источником звука ГТД, попадает на внешнюю звукопроницаемую обшивку 6 (рис. 2) звукоизоляционной панели, частично отражается от нее и рассеивается. При этом основная часть звуковой энергии проникает через внешнюю звукопроницаемую обшивку 6 в слои заполнителя. Попадая в гофрированный слой 8, звук многократно переотражается и поглощается параболическими поверхностями рядов звукоотражающих элементов 13 (рефлекторов), фокусируясь в отдельные пятна. Пятна фокусировки расположены на промежуточном слое 11. Их место расположения определяется продольной осью отдельного ряда звукоотражающих элементов 13, которая перпендикулярна вертикальной оси (оси симметрии) рассмотренных параболических поверхностей. При этом часть акустической энергии, которая попала на криволинейные поверхности 14, веерообразно рассеивается в пространстве между внутренней обшивкой 6 и промежуточным слоем 11. Концентрированная в пятно отдельными рядами звукоотражающих элементов 13 энергия звука вызывает вибрацию промежуточного слоя 11 и поглощается им. Эффективное звукопоглощение происходит благодаря композиционному материалу, в частности, углепластику, который имеет высокий коэффициент поглощения акустической энергии.

При последующем рассеянии звук попадает в гофрированный слой 9, который состоит из идентич- 


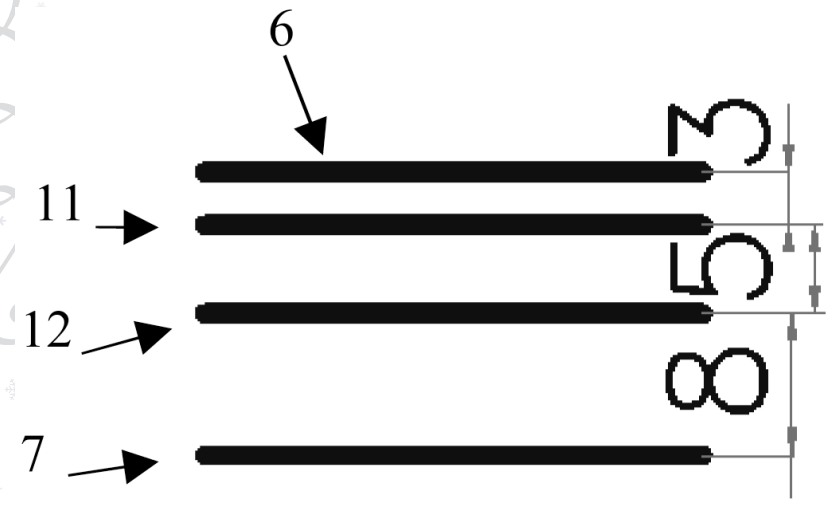

Рис. 4. Пропорции расстояния (в соответствии с рядом чисел Фибоначчи) между слоями $6,11,12$ и 7 в конструкции панели

ных, по аналогии с гофрированным слоем 8, рядов звукоотражающих элементов 13. При этом гофрированный слой 9 расположен под углом к гофрированному слою 8, в данном случае, они перпендикулярны друг другу. Такое расположение гофрированных слоев 8 и 9 приводит к дроблению звукового потока для более эффективного звукопоглощения. В гофрированном слое 9 происходят те же звуковые процессы, что и в гофрированном слое 8. Промежуточный слой 12 по выполняемым функциям и конструктивным особенностям аналогичен промежуточному слою 11. В связи с тем, что внешняя обшивка 7 не является звукопоглощающим слоем, а обеспечивает жесткость конструкции всей звукоизоляционной панели, гофрированный слой 10 является крайним, замыкающим, звукопоглощающим слоем.

Собственные частоты вибрирующих гофрированных слоев 8, 9 и 10 формируются конструкцией панели, находятся в отношении, близком к иррациональному равному числу Фибоначчи (см. рис. 4). Причем, расстояние между слоем 6 и 11 находится в зависимости от необходимой общей толщины панели шумоглушения. Суперпозиция процессов вибраций слоев будет иметь модулируемую огибающую частоту, которая находится в низкочастотной (слабослышимой) области спектра. Процесс вибрации слоев с этой частотой определяет механический процесс диссипации энергии источника звука в материале панели и реализацию позитивного эффекта - изоляции источника звука от приемника.

Таким образом, эффект звукоизоляции обеспечивается путем суперпозиции процессов внутреннего отражения и поглощения энергии звуковой волны, которая повышает эффективность разработанной звукоизоляционной панели.

\section{4. Подготовка и проведение экспериментов}

В связи с тем, что разработанная конструкция панели шумопоглощения не имеет перфорации по слою 6, испытания выполнялись не в камере с потоком (скорость потока влияет на смещение частотных характеристик панелей с сотовым заполнителем, соты которого представляют собой резонаторы Гельмгольца, настроенные на выбранную частоту излучения элементов), а в безэховой камере. Для проведения испытаний панели была разработана и изготовлена конструкция безэховой камеры, которая представляет собой короб, заполненный звукопоглощающими материалами (поролон, пористая резина и вспененный полиэтилен). По центру короба находится прямоугольная камера, разделенная (на 2 равных объема) вставляемой звукоизолирующей панелью. В одной полу-камере располагается широкополосный динамик, во второй - широкополосный микрофон. На динамик подается сигнал, представляющий собой «белый шум», микрофон воспринимает сигнал, прошедший через, разделяющую объемы, звукоизолирующую панель. Полученные данные обрабатывались и сравнивались с базовой моделью панели (см. рис. 1). Для проведения сравнительных испытаний, были взяты за базу характеристики двухслойной звукопоглощающей панели. Были изготовлены 13 вариантов образцов звукопоглощающих панелей, включая: применяемые на двигателях сотовые панели с титановой перфорированной поверхностью, перфорированные трубчатые и др. в различных вариантах используемых материалов. С целью получения более достоверных результатов, испытания проводились ночью в нерабочий день.

\section{5. Анализ результатов экспериментальных исследований}

Эффективность технического решения экспериментально определялась расчетом функции коэффициента прозрачности разработанной панели (обратная величина коэффициента затухания) в частотной области. Экспериментальные исследования, проведенные в безэховой камере, показали, что разработанная звукоизоляционная панель ГТд, как минимум, на один децибел мощности $(\mathrm{dBm})$ эффективнее панели классической схемы аналога (прозрачность которого принята за $0 \mathrm{dBm}$, см. рис. 5) в эффективном звуковом диапазоне частот, который определяется международными нормативными документами. Анализ функции в низкочастотной области спектра (ниже 300 Гц) позволяет сделать вывод о наличии механических процессов диссипации энергии звука и эффективности предложенных иррациональных отношений размеров конструктивных элементов. Результаты экспериментальных исследований позволяют предполагать, что разработанные и испытанные в ГП «Ивченко-Прогресс» звукопоглощающие конструкции, за счет высокой эффек- 


\section{4/2018 ПехнологическиETC}
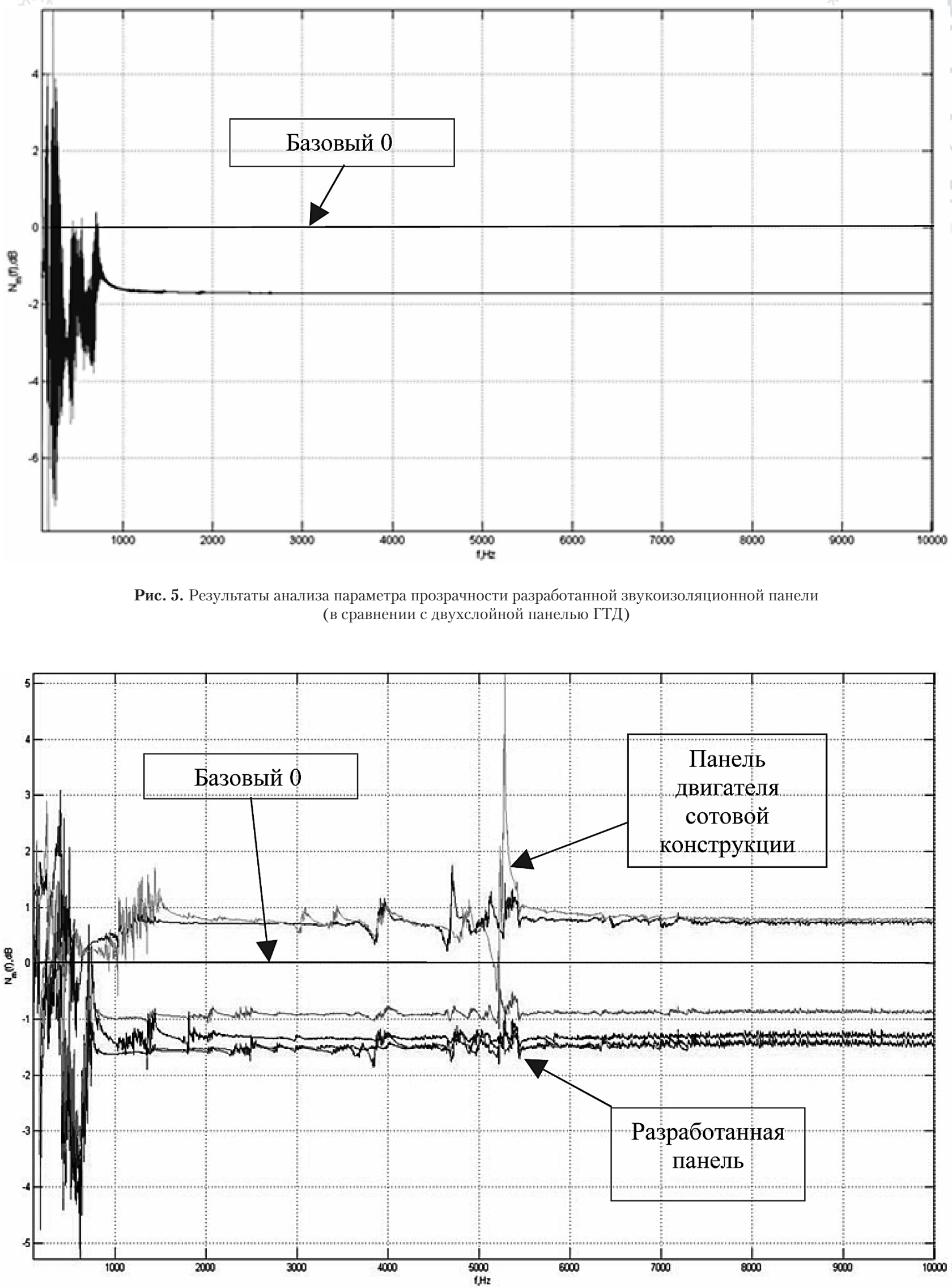

Рис. 6. Результаты анализа параметров различных вариантов звукоизоляционных панелей (в сравнении с двухслойной панелью ГТД) 
тивности в широком диапазоне частот, позволят самолету с этими двигателями удовлетворять существующим нормам Главы 4 IКАО.

\section{6. Выводы}

Повышение эффективности звукоизоляционной панели ГТД в стандартном диапазоне частот шума достигается путем рационального подбора параметров геометрической конструкции, материалов и размеров звукопоглощающих слоев выполненных композитных материалов, их взаимного расположения, а также выбора соотношения размеров слоев.

\section{7. Литература}

[1] «Конвенции о международной гражданской авиации». Приложение 16 «Охрана окружающей среды», том 1 «Авиационный шум», раздел «Авиационная акустика».

[2] Каблов Е.Н. Стратегические направления развития материалов и технологий их переработки на период до 2030 года [Текст] / Е.Н. Каблов //Авиационные материалы и технологии: Юбилейный науч.-техн.сб. (приложение к журналу «Авиационные материалы и технологии»). - М.: ВИАМ, 2012. - С. 7-17.

[3] Авиационная акустика. - Ч.1 [Текст] / - М.: Машиностроение, 1986. - 244 с.

[4] Авторское свидетельство СССР № 1038260 «Многослойная панель». Заявлено 28.08.1983г., кл. МПК 6 В 32 В 3/28, Е 04 2/24

[5] Патент Российской Федерации № 2307216 «Звукопоглощающая панель» від 27.09.2007, кл. МПК 7 Е 04 В 1/86, G 10 K 11/16.

[6] Патент Украины № 106294 «Звукоізоляційна панель газутурбінного двигуна» от 25.04.2016 кл. МПК G01K 11/16, F02B 55/08.

Jalovenko E. V., Zhuravlev V.N.

Zaporozhye Machine-Building Design Bureau Progress State Enterprise named after Academician A. G. Ivchenko. Ukraine, Zaporozhye

\section{SOUND ABSORBING PANEL OF TURBO-ENGINE ON BASE OF IRRATIONAL FIBONACCI}

Solution of task of absorption of noises is offered, including, for turbo-engines, by the method of selection of frequency constituents of noise of engine, that are in irrational correlation with subsequent dissipation of their energy in the elements of construction. The construction of panel and applied materials, in particular black-reinforced plastic, provide maximal absorption of energy of frequency constituents. [dx.doi.org/10.29010/085.11]

Keywords: Turbo-engines; sound absorbing panel; black-reinforced plastic; a Fibonacci number.

\section{References}

[1] «Konvencii o mezhdunarodnoj grazhdanskoj aviacii». Prilozhenie 16 «Ohrana okruzhajushhej sredy», tom 1 «Aviacionnyj shum», razdel «Aviacionnaja akustika».

[2] Kablov E.N. Strategicheskie napravlenija razvitija materialov i tehnologij ih pererabotki na period do 2030 goda [Text] / E.N. Kablov //Aviacionnye materialy i tehnologii: Jubilejnyj nauch.-tehn.sb. (prilozhenie k zhurnalu «Aviacionnye materialy i tehnologii»). - M.: VIAM, 2012. - P. 7-17.

[3] Aviacionnaja akustika. - Ch.1 [Text] / - M.: Mashinostroenie, 1986. - 244 p..

[4] Avtorskoe svidetelstvo SSSR № 1038260 «Mnogoslojnaja panel'». Zajavleno 28.08.1983g., kl. MPK 6 V 32 V 3/28, E $042 / 24$.

[5] Patent Rossijskoj Federacii № 2307216 «Zvukopogloshhajushhaja panel» vid 27.09.2007, kl. MPK 7 E 04 B 1/86, G 10 K $11 / 16$.

[6] Patent Ukrainy № 106294 «Zvukoizoljacijna panel gazuturbinnogo dviguna» ot 25.04.2016 kl. MPK G01K 11/16, F02B 55/08. 